\title{
The Effects of Driver Licensing Laws on Immigrant Travel
}

\author{
Jesus M. Barajas \\ University of California, Davis \\ jmbarajas@ucdavis.edu
}

March 9, 2021

\begin{abstract}
Car use is critical to improving access to opportunities, especially for low-wage immigrants whose jobs are dispersed and when transit service is minimal. But many states have restricted the ability of undocumented immigrants to obtain drivers licenses, making it potentially difficult for them to improve their economic standing. The effects of these laws have been tested for their association with traffic safety but not on mode choice itself. Using the two most recent versions of the National Household Travel Survey, I fit a series of difference-in-difference models to estimate the effect of permissive immigrant driver licensing on travel outcomes. Permissive licensing increased the rate of giving rides by about $13 \%$ and increased the rate of getting a ride by about $6.5 \%$, but changes to driving alone were insignificant. Results suggest permissive licensing has beneficial accessibility impacts for all immigrants in addition to the positive safety and economic externalities documented elsewhere.

Keywords: travel behavior; transportation equity; immigrants; driver licensing; carpooling; difference-indifference estimation
\end{abstract}

\section{Introduction}

While planners and policymakers often seek to encourage alternatives to private auto use through priorities such as transit service, pedestrian and bicycle infrastructure, compact land development, and road pricing, the reality of metropolitan land structure and the distribution of opportunities in the United States makes it extremely difficult to navigate life without a car. Car ownership and use increases access to jobs and essential services, even in central city locations where public transit has a spatial advantage (Grengs 2010,2012). And though early in the 2000s city growth outpaced suburban growth giving a boost to transit ridership, the suburbs continued to add people and have now recaptured the majority of population growth (Frey 2018). In most of the country, the dominance of the private automobile looks to be secure because it is an essential tool for mobility.

These trends have special relevance for immigrants to the United States. Although migrants seeking new opportunities continue to settle in traditional sites of immigration such as New York, Los Angeles, and Chicago, increasingly they are choosing to live in smaller metropolitan areas or to bypass central cities for suburbs where alternative transportation options are less robust (Wilson and Svajlenka 2014; Snyder 2015). Particularly for low-income immigrants with few financial resources, cars can be important tools to prevent workers from staying in or straying into poverty. Those with access to vehicles tend to find jobs and keep them even if public transit is easily accessible (Ong 2002; Cervero, Sandoval, and Landis 2002; Blumenberg 2016). In places like the southern United States where immigration is a newer phenomenon, lack of access to a vehicle can both restrict personal opportunity and lead to cultural isolation if people must self-segregate into neighborhoods where public transit is a feasible alternative (Bohon, Stamps, and Atiles 2008).

Those who lack the proper documentation for residence in the United States face further restrictions on car access: most states limit the issuance of drivers licenses to those who can prove legal entry as a permanent resident and to citizens. Nevertheless, 17 jurisdictions in the United States permit undocumented immigrants to obtain licenses (National Conference of State Legislatures 2020), with other state legislatures periodically submitting bills to allow it. Approximately 11 million undocumented immigrants live in the United States (Passel and Cohn 2018) and over 4 million, or about 5 percent of all immigrants, live in states where they are eligible to obtain drivers licenses. However, of the ten states with the highest number of undocumented immigrants, only New York, California, and Illinois permit 
undocumented immigrants to drive - with New York having passed legislation only within the last year-suggesting a significant disparity in access to opportunities. While the effects of these laws have been analyzed for their secondorder impacts related to car use such as traffic safety, no study has yet investigated how permissive licensing affects car use itself among immigrants. This study addresses this gap in the travel behavior literature. In this paper, I present results from several difference-in-difference models that test the effects of permissive licensing laws on immigrant travel using nationally-representative daily trip data. I find that immigrants who live in states that passed such laws carpooled slightly more often and were more likely to switch from transit to driving after the laws were implemented. There was no significant change in vehicle miles traveled (VMT) generated or in the number of trips driven alone. In the remainder of this paper, I describe the context of immigrant travel and driver licensing laws and argue, given the results of the study, for the importance of immigrant-supportive driver licensing as a transportation equity issue.

\section{Immigration, car use, and licensing laws}

\subsection{Immigrant travel behavior}

Immigrants to the United States are less likely to drive than their US-born counterparts even after controlling for a variety of socioeconomic and built environment characteristics (Blumenberg 2009; Chatman and Klein 2009; Tal and Handy 2010; Chatman 2014). Nevertheless, car use remains a critical component of the set of immigrants' travel options, and carpooling particularly so. Immigrants are more likely to form carpools with both household members and others than the US-born even when presented with the option to take public transportation (Blumenberg and Smart 2010). Some research suggests that immigrants who live in ethnic enclaves - that is, neighborhoods with higher than average concentrations of immigrants - carpool more than people living in other neighborhoods (Liu and Painter 2012; Blumenberg and Smart 2014; Smart 2015; Shin 2017), reflecting social network effects and resource sharing that make travel easier. These network effects facilitate a degree of car access even if individuals do not own cars themselves. However, limited incomes or lack of drivers licenses among car owners restrict the extent to which they can lend vehicles or give rides (Lovejoy and Handy 2008, 2011). Other research finds that lower rates of solo driving can be better explained by neighborhood preferences, such as living in compact built environments (Chatman 2014), or by occupational characteristics associated with employment in ethnic niche industries or jobs that immigrants commonly hold (Liu and Painter 2012; Chatman and Klein 2011). Factors unique to the immigrant experience, such as sending remittances to family in home countries or differences in cultural attitudes toward driving, slow or prevent adopting driving alone as a primary mode of travel even across income levels and experiences (Chatman and Klein 2013; Barajas 2020). Latino immigrants who are undocumented commute by car less than those with legal status, yet two-thirds still usually drive to work (Allen and Wang 2020).

Because most studies that explore the travel behavior of immigrants rely on general travel surveys or census commuting characteristics, they do not address other barriers to driving that are difficult to quantify. Policing practices, for example, foster a landscape of exclusion for undocumented immigrants by creating a fearful environment that they must navigate in their daily mobility practices. Relying on extensive ethnographic data, researchers documented how immigration enforcement assumed by state and local police in Atlanta, Georgia, impacted the mobility of undocumented immigrants in that city (Stuesse and Coleman 2014). The Secure Communities and 287(g) programs in Georgia permitted police to act as an extension of federal immigration enforcement by allowing them to detain individuals suspected of immigration violations, usually implemented through traffic enforcement. According to their interviewees, police established traffic checkpoints in primarily Latino neighborhoods, prompting many to move out of their homes for other places perceived to be more immigrant-friendly. Some stopped working out of fear of being stopped by police while driving. The authors also found that undocumented individuals drove less, relied on their social networks to get rides, or purchased rides from documented immigrant drivers for errands. Other research finds that even when people get rides rather than drive, they know they may place the drivers at risk because not all ride-givers are licensed themselves, or if they are, may not have adequate insurance coverage (Lovejoy and Handy 2011).

Apart from instilling fear, policing mobility has consequences that result from restricted movement. For example, after Arizona passed SB 1070, a law that required local law enforcement to ask about immigration status upon contact with individuals, adolescent mothers of Mexican origin were less likely to take their babies to a doctor for routine health care (Toomey et al. 2014). On the other hand, undocumented immigrants have had opportunities become more available to them once they were able to obtain licenses. The Deferred Action for Childhood Arrival (DACA) policy allowed young adults who were previously undocumented but had lived in the United States since childhood to have 
their immigration status semi-regularized. A study of DACA recipients found that 57 percent had obtained licenses after receiving deferred action, 59 percent had obtained a job, and 45 percent had increased their earnings at their current jobs (Gonzales, Terriquez, and Ruszczyk 2014). The relatively high proportion of DACA recipients who got driving privileges indicates there was a latent demand for legal driving, which increased socioeconomic status by way of improved mobility.

\subsection{Safety effects of changes in licensing laws}

Competing policy priorities changed the landscape of driver licensing for immigrants in the United States over the past two decades. Partially in response to greater security concerns and federal government requirements such as the REAL ID act, most states require individuals to prove lawful residence in the United States prior to obtaining a license. In 1990, only 14 states had laws requiring documented presence or possession of a social security number to obtain a license. By 2011, all but two jurisdictions that issue drivers licenses had passed such laws (Cáceres and Jameson 2015). At the same time, however, an increasing number of states began to issue licenses to individuals who could prove that they lived in the state regardless of their immigration status. Washington State passed the first such law in 1993, which permitted individuals to show proof of residence or provide a tax identification number of in lieu of a Social Security Number to apply for a drivers license. By 2017, 12 states and the District of Columbia had allowed undocumented immigrants who live in those states to obtain driving privileges (National Conference of State Legislatures 2020).

Both license restrictions and permissive licensing have had measurable effects on insurance costs and traffic safety. When undocumented immigrants are unable to obtain licenses, they are also unable to purchase auto insurance whether or not they drive in contravention of the law. Controlling for factors such as the number of cars, car thefts, and fatal crashes, the net effect of restrictive licensing has been to raise average individual insurance expenditures by about $\$ 20$ in current dollars (Cáceres and Jameson 2015). After the passage of Assembly Bill (AB) 60 in California in January 2015, a law allowing undocumented immigrants to obtain driving privileges, insurance costs decreased and traffic safety improved. Using statewide data from January 2006 to December 2015, researchers found no effects of the law on the total number of crashes per capita or the number of fatal crashes as a proportion of total crashes (Lueders, Hainmueller, and Lawrence 2017). Counties that issued more licenses under AB 60 provisions had fewer hit-and-run crashes, however, resulting in an estimated $\$ 17$ million in economic efficiency from recovered insurance costs. The authors found that the law was more likely to have legalized driving for those who were already driving without a license rather than to have attracted brand new drivers. Where cars are necessary because there are no alternatives, people will drive.

\section{Data and methodology}

This study estimates the effects of driver licensing laws on immigrant travel. For simplicity, I refer to states that passed driver licensing laws that permit undocumented immigrants to drive as "permissive license law" states. I ask three related research questions about immigrant travel and permissive laws:

1. Have permissive license laws affected vehicle miles traveled (VMT)?

2. Have permissive license laws affected the number of driving and carpooling trips?

3. Have permissive license laws affected mode choice?

Permissive license laws only directly affect immigrants without legal authorization to reside in the country; immigrants with regular visa status, permanent residents, and US citizenship are normally eligible to obtain a license. Thus, the effects of permissive license laws on driving should be relatively small in aggregate given that undocumented immigrants make up roughly a quarter of all immigrants to the US. However, states with permissive license laws may also have political and cultural climates that are more welcoming of immigrants, allowing them to feel more comfortable in accessing public services such as visiting government offices to obtain a license. Permissive license laws may therefore increase the likelihood of driving among all immigrant groups.

\subsection{Driving distance and mode choice}

Travel data comes from restricted-use versions of the two most recent National Household Travel Surveys (NHTS), conducted in 2009 and 2017. The restricted-use versions add census tract identifiers to the same information available 
in public use data sets, which allows for the use of more detailed built environment data to better control for factors associated with travel. Note that neither dataset includes information about the documentation status of immigrants, so it is not possible to isolate effects at a level of detail more than whether an individual was born in the United States. I used data from the National Conference of State Legislatures (2020) to identify the states with permissive license laws. In 2009, three states had permissive laws: Washington, Utah, and New Mexico. By 2017, California, Colorado, Connecticut, Delaware, Hawaii, Illinois, Maryland, Nevada, Vermont, and the District of Columbia had enacted similar legislation.

Permissive license laws have small associations with immigrant driving trips. Figure 1 shows the differences in weighted average household VMT and individual miles driven across survey year, immigrant status, and license law status. ${ }^{1}$ In both 2009 and 2017, average VMT for households composed of only US-born residents was higher in states that did not have a permissive license law; households drove about 5 miles more in 2009 and 3 miles more in 2017 in those states. Because permissive licensing should not have an effect on non-immigrant travel behavior, the licensing variable is capturing unobserved built environment and transportation system characteristics that contribute to fewer miles driven in immigrant households. For households that have at least one foreign-born resident, there were no differences in household VMT by license law status suggesting that the laws may mitigate the effects of uncontrolled variables. The patterns were similar at the individual level. There was no statistically significant difference between immigrants and the US-born in average miles driven in 2009 in permissive law states, but in other states the US-born drove an average of 2.5 miles more per day. In 2017, however, personal miles driven followed similar patterns as household VMT. US-born individuals drove an average of 2 miles less per day in permissive law states, while there was no difference for immigrants.

Patterns of mode choice were more consistent with the hypothesis that permissive license laws have an influence on how much immigrants drive (Figure 2). In 2009, US-born individuals made about $84 \%$ of their trips by private vehicle. Immigrants who lived in permissive law states made a greater share of their trips by car: $86 \%$ of trips were auto trips compared to $75 \%$ of trips in states without permissive license laws. The share of carpool trips made up most of the difference, which was 10 percentage points higher in permissive law states that year. The share of driving trips was also higher among immigrants in 2017, though the difference between permissive law and non-permissive law states was much smaller. Immigrants made one third of their trips by driving alone in both places. Permissive law states had only slightly higher rates of carpooling than other states in 2017.

\subsection{Does the NHTS sample include undocumented immigrants?}

A perennial concern of survey researchers is non-response of hard-to-survey groups, a category that generally includes undocumented immigrants. For example, to ensure accurate population counts in the US Census, which is compulsory for all residents, states spent several million dollars to fund additional outreach for the 2020 count (Wines and Real 2019). This is for good reason: the undocumented population makes up about a quarter of the 44.7 million US immigrants (Passel and Cohn 2018). There is no direct evidence of the extent to which undocumented immigrants are represented in the NHTS. The only questions that address immigration ask whether the respondents were born in the US and when they arrived. We can say that all immigrants are undercounted, however. In $2009,8.4 \%$ of NHTS respondents were foreign-born while in 2017,9.7\% of respondents were - both under-estimates of about four percentage points compared to figures from the American Community Survey (U. S. Census Bureau 2010, 2018).

We might extrapolate from other surveys that have more information about immigrant status to understand the potential magnitude of underrepresentation in the NHTS. Bachmeier, Van Hook, and Bean (2014) examined non-response rates and survey attrition in two surveys that asked immigrants about their legal status, presumed to be a particularly sensitive question. One was the Survey of Income and Program Participation (SIPP) administered by the US Census Bureau. They found that compared to the best national estimates, the survey undercounted the proportion of undocumented immigrants by about 9 percentage points. And while they found that non-response and attrition between panel waves in SIPP was higher among undocumented immigrants compared to legal non-citizens and naturalized citizens, their

\footnotetext{
${ }^{1}$ In 2017, the NHTS changed the methodology by which it computed distance traveled. In previous editions of the survey, travel distance was self-reported. Now, it is calculated as the shortest network distance between origin and destination locations. There was an apparent decline in VMT in 2017 attributed to the change in data collection methods. While not a problem when analyzing data for a single year, it makes comparisons across years more difficult. McGuckin and Fucci (2018) suggest an adjustment to travel distance to make the two datasets more comparable: distance traveled in 2017 is multiplied by 1.0735 miles for work trips and by 1.1151 miles for non-work trips. I make the same adjustments throughout this paper. Mileage adjustments were also calculated in a recent public data release to the NHTS, but this study was completed before that update.
} 




Figure 1: VMT and miles driven by immigrant status, survey year, and license law status 


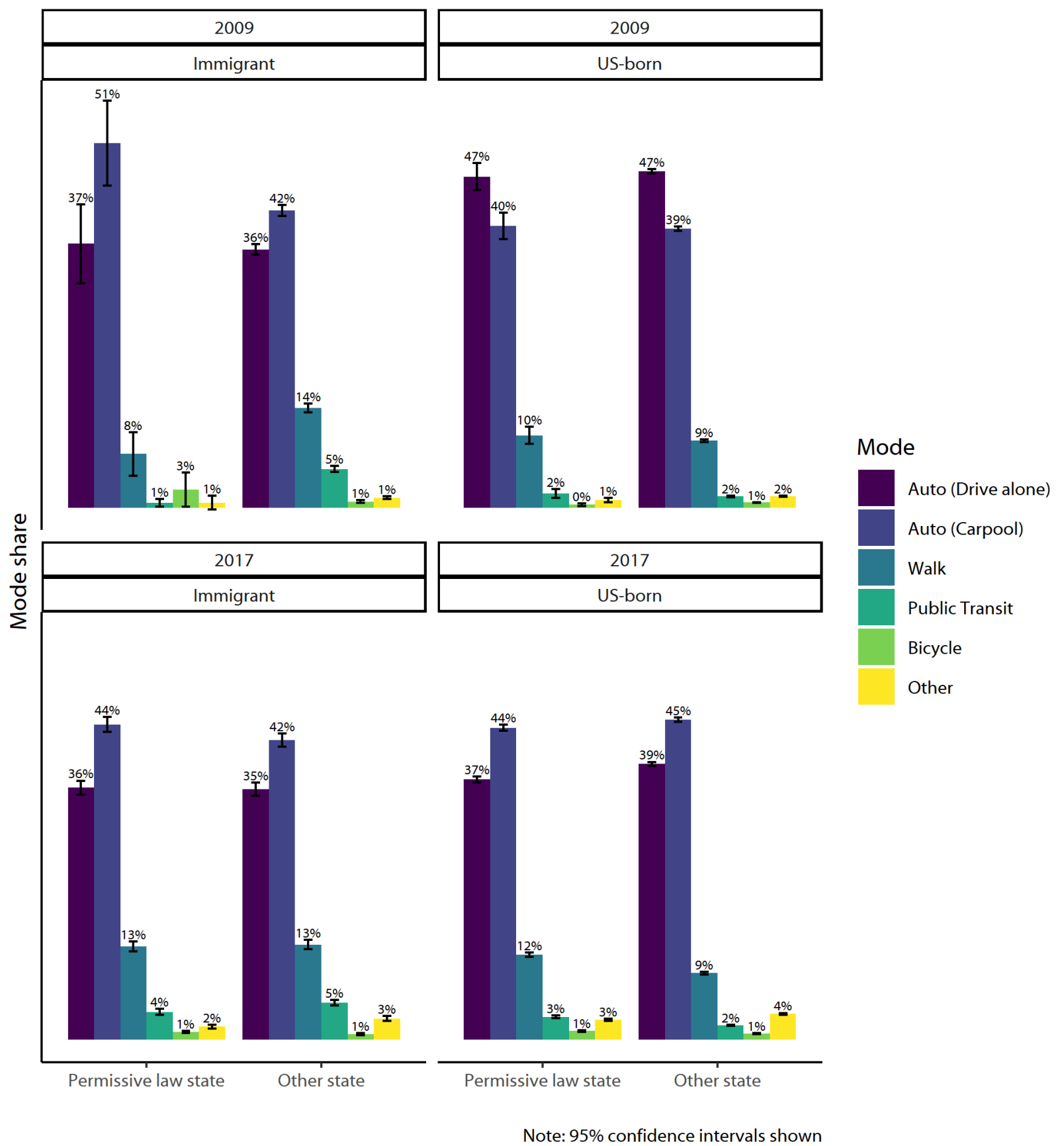

Figure 2: Mode share (weighted) by year and immigrant status 
overall rates of non-response were between 5 and 7 percent and rates of attrition were between 14 and 18 percent. In other words, undocumented immigrants were underrepresented in the survey but were far from absent. Other national and large-metro surveys with questions about immigrants' legal status reported non-response rates among presumed undocumented immigrants lower than SIPP. Thus, in a survey with fewer sensitive questions about immigrant status such as the NHTS, I assume the sample includes a reasonable share of the total undocumented population.

\subsection{Toward causal inference: A difference-in-difference approach}

Determining the causal effects of a policy generally requires a quasi-experimental research design because it relies on detecting patterns from observational data rather than from a randomized controlled experiment. Difference-indifference (DiD) models can be used to estimate such causal effects. They estimate the average treatment effect of an intervention on a treated group compared to a counterfactual situation in a control group where the policy had not been implemented (Gelman and Hill 2007). In this study, the intervention refers to the implementation of a permissive license law. In other transportation research, DiD methods have been used to analyze, for example, the effects of driving restrictions on pollution, the effects of light rail on real estate development, and changes in physical activity resulting from the installation of bicycle boulevards (Gallego, Montero, and Salas 2013; Cao and Porter-Nelson 2016; Dill et al. 2014).

\subsubsection{Modeling requirements}

The DiD approach is illustrated in Figure 3. Observations used in the models can be partitioned into four categories represented by $A$ to $D$ in the figure: whether the observations are from the period before $(A$ and $C)$ or after $(B$ and $D)$ permissive laws were enacted, and whether the observations were in a state that implemented the laws $(A$ and $B)$ or not $(C$ and $D)$. In the absence of any policy, the expected trends in travel outcomes - namely VMT, trip frequency, and mode choice - are given by $D-C$. A naive interpretation of the policy effect is given by $B-A$; however, the true effect of the policy is the difference from the expected trend, or $(B-A)-(D-C)$. DiD estimation uses regression modeling with a functional form appropriate for analysis. DiD models include a dummy term for time, a dummy term for treatment group, and an interaction term of the two. The DiD estimator — that is, the policy effect-is given by the coefficient of the interaction term.

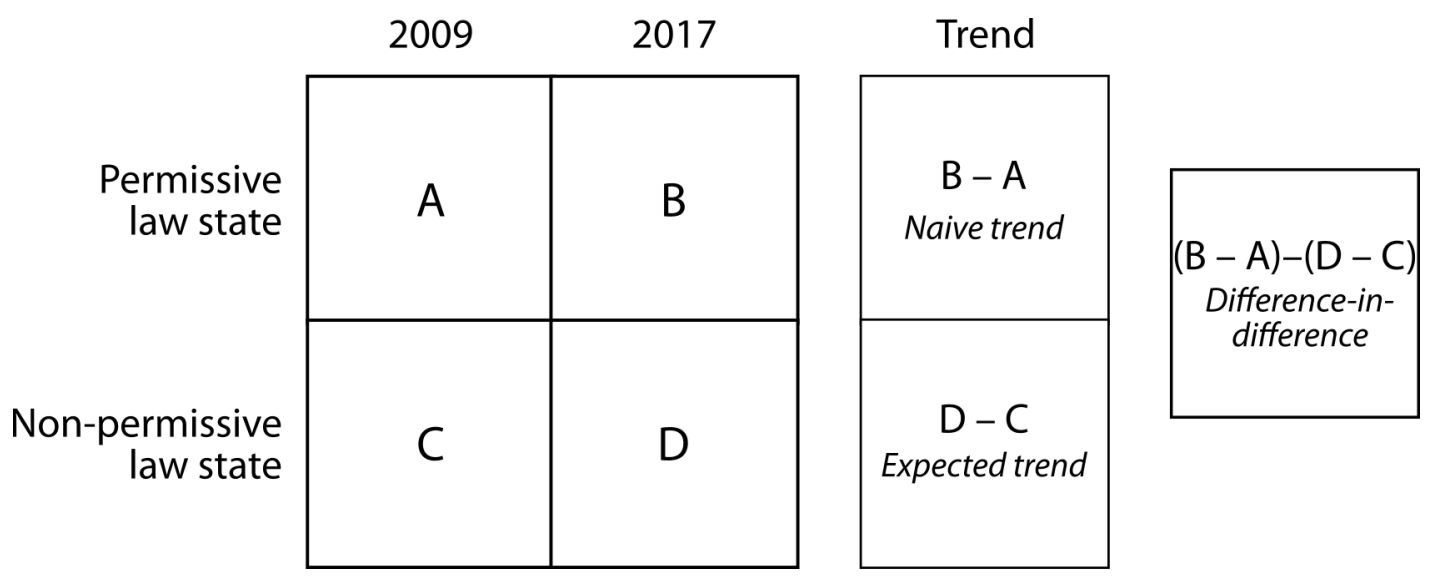

Figure 3: Difference-in-difference model schematic

Two assumptions must be addressed in DiD estimation (Wing, Simon, and Bello-Gomez 2018). First, accurate estimation requires common trends across treatment groups; in other words, $D-C$ should be parallel to $B-A$ before the intervention period. It is not possible to test this assumption over two time points. The second assumption is stability of group composition. In a repeated cross-section study, there is no way of guaranteeing (or knowing) whether the same individuals remained in the study during the two time periods. In fact, it is very likely that the individuals are completely different between the two survey waves. Instability is not a problem per se but becomes a problem when treatment assignment changes systematically with changes in covariates over time (Wing, Simon, and Bello-Gomez 
2018, 460). For example, states with permissive license laws could attract more undocumented immigrants, changing the composition of the population and making it difficult to determine the effects of the laws themselves.

\subsubsection{Propensity score matching}

A common way to resolve systematic bias associated with unknown trend lines and changing group composition is the use of propensity score matching. Propensity scores reflect how close individuals are on a set of covariates, for varying definitions of closeness (Stuart 2010). Multiple estimation methods exist for generating propensity scores, the most common of which is multinomial logistic regression to predict group membership. Note that propensity score weighting would introduce bias in population-level predictions of travel outcomes by further making the sample unrepresentative. However, this study is measuring the average treatment effect on the treated rather than population measures; in other words, the quantity of interest is an estimate of the effect of permissive licensing on travel behavior for immigrants who lived in those states. Rosenbaum and Rubin (1983) show that propensity scores used to balance groups based on a set of observed covariates produce unbiased estimates of such treatment effects.

In specifying propensity score models, all variables related to both the outcome and treatment assignment should be included but any variable affected by the program should be excluded (Stuart 2010; Stuart et al. 2014). In this study, it is possible that permissive licensing laws attracted immigrants to states where those laws were implemented. Summary statistics in Table 1 indicate that immigrants in permissive law states were on average older, longer tenured, and less likely to live in a predominately immigrant neighborhood, suggesting that policy implementation might not be encouraging residential relocation. Nevertheless, I account for possible association by excluding these variables from the propensity score weighting estimation because of the potential to condition out the effect of permissive licensing. They are included in the regression models that predict outcomes of interest, however. Gas prices are highly correlated with state of residence - and thus study treatment - so I also excluded this variable. All other control variables, described in more detail in section 3.3.3, are included in the propensity score model.

I used the WeightIt and cobalt packages in R to estimate propensity score weights and assess balance across covariates (Griefer 2019b, 2019a). The pre-treatment treated group is the baseline for comparison. All observations in group $A$ (Figure 3) were weighted as 1 and observations in other groups were weighted to achieve a similar composition. Statistical significance is not a concern in propensity score weighting; rather, the applicable measure of fit for each variable is the standardized mean difference between the treated group and control groups. (In the case of multinomial outcomes, difference reported is the maximum standardized mean difference.) A standardized mean difference of 0.1 is a commonly accepted upper level. Variance ratios for continuous measured variables are reported to be good if less than 1.2. The balance summary indicated the model met these measures of fit (Figure 4). The resulting propensity score weights were then used in model estimation for each of the research questions.

\subsubsection{Model specification}

The three research questions require different parametric forms of the regression models. The first, an estimate of personal VMT, uses a tobit model. Tobit models are appropriate for data that is bounded or limited (McDonald and Moffitt 1980). In the case of this analysis, VMT is naturally limited at zero. Two processes generate the incidence of zero VMT: people who did not drive on the travel day (but may drive otherwise), and people who cannot drive or did not drive because they do not have a vehicle. The model simultaneously estimates the probability that VMT is greater than 0 given the set of covariates and the expected value of VMT conditional on VMT being greater than 0 . VMT is substantially right-skewed; in model estimation, I log transformed VMT +1 to create a normally-distributed variable. The second, estimates of trips driven, rides taken, and rides given, require count models. I selected negative binomial models as the proper estimating forms for all three quantities because the data was significantly overdispersed. Negative binomial models relax the Poisson assumption that means and variances are equal, correctly modeling overdispersion.

The third question requires discrete choice analysis. I estimated a multinomial logistic regression model of mode choice, simplified from the NHTS categories into drive alone, carpool, transit, non-motorized (i.e. walking and cycling), and other. I tested standard logit models and nested models for goodness of fit. A nested structure with driving and carpooling in their own nests and the remaining three modes in a third nest minimized the log-likelihood of the model, so I selected that as the final model. For brevity, I omit "other" modes from the interpretation in the text since this category contains a mix of travel modes that differ in characteristics. 
Table 1: Comparison of immigrant characteristics between permissive law and non-permissive law states, 2009 and 2017

\begin{tabular}{|c|c|c|c|c|c|c|c|}
\hline \multirow[b]{2}{*}{ Variable } & \multirow[b]{2}{*}{ Value } & \multicolumn{3}{|c|}{2009} & \multicolumn{3}{|c|}{2017} \\
\hline & & No law & Law & Sig. & No law & Law & Sig. \\
\hline Num. children & Mean & 1.1 & 1.3 & $* * *$ & 0.9 & 0.9 & \\
\hline Yrs. since immigration & Mean & 22.0 & 21.8 & & 21.3 & 24.1 & $* * *$ \\
\hline Age & Mean & 43.2 & 42.5 & & 42.8 & 44.8 & $* * *$ \\
\hline Vehicles per hh. driver & Mean & 0.9 & 0.9 & * & 0.9 & 1.0 & $* * *$ \\
\hline Tract pop. dens. (per $\mathrm{km}^{2}$ ) & Mean & 4989.7 & 3879.0 & $* * *$ & 4378.9 & 3608.1 & $* *$ \\
\hline Tract renters $(\%)$ & Mean & 38.6 & 45.6 & $* * *$ & 41.9 & 44.9 & $* *$ \\
\hline Tract poverty rate $(\%)$ & Mean & 0.1 & 0.1 & & 0.1 & 0.1 & \\
\hline Gender $(\%)$ & Female & 50.5 & 51.3 & & 50.9 & 50.9 & \\
\hline \multirow[t]{5}{*}{ Income quintile (\%) } & 1 & 30.1 & 35.5 & * & 21.5 & 20.6 & \\
\hline & 2 & 20.2 & 22.3 & $*$ & 22.9 & 20.6 & \\
\hline & 3 & 14.7 & 12.6 & $*$ & 15.5 & 16.5 & \\
\hline & 4 & 15.6 & 12.9 & $*$ & 20.6 & 21.3 & \\
\hline & 5 & 19.3 & 16.7 & $*$ & 19.5 & 21.0 & \\
\hline \multirow[t]{5}{*}{ Race/ethnicity (\%) } & White & 26.5 & 20.9 & $* * *$ & 26.1 & 24.2 & $* *$ \\
\hline & Black or African American & 10.8 & 3.6 & $* * *$ & 11.4 & 5.5 & $* *$ \\
\hline & Hispanic/Latino & 45.5 & 55.1 & $* * *$ & 37.1 & 40.3 & $* *$ \\
\hline & Asian & 13.0 & 17.3 & $* * *$ & 22.5 & 26.6 & $* *$ \\
\hline & Other & 4.2 & 3.1 & $* * *$ & 2.9 & 3.4 & $* *$ \\
\hline \multirow[t]{4}{*}{ Educ. attain. (\%) } & Less than high school & 19.0 & 26.6 & $* * *$ & 11.1 & 15.2 & $* * *$ \\
\hline & High school graduate & 41.8 & 41.9 & $* * *$ & 36.2 & 38.9 & $* * *$ \\
\hline & College graduate & 37.3 & 30.1 & $* * *$ & 48.0 & 41.8 & $* * *$ \\
\hline & Currently in school & 1.9 & 1.5 & $* * *$ & 4.8 & 4.1 & $* * *$ \\
\hline Homeownership (\%) & Rent & 40.9 & 54.8 & $* * *$ & 43.6 & 46.6 & \\
\hline Employment (\%) & Employed & 67.0 & 67.6 & & 69.0 & 66.1 & $*$ \\
\hline \multirow[t]{6}{*}{ Urban size (\%) } & Not in an urbanized area & 17.0 & 10.8 & $* * *$ & 10.9 & 5.9 & $* * *$ \\
\hline & $50,000-199,999$ & 6.6 & 7.2 & $* * *$ & 7.1 & 8.4 & $* * *$ \\
\hline & $200,000-499,999$ & 8.1 & 6.5 & $* * *$ & 10.9 & 5.8 & $* * *$ \\
\hline & $500,000-999,999$ & 7.7 & 7.5 & $* * *$ & 8.4 & 8.4 & $* * *$ \\
\hline & 1 million + , no heavy rail & 20.3 & 19.2 & $* * *$ & 25.0 & 13.5 & $* * *$ \\
\hline & 1 million + , heavy rail & 40.3 & 48.9 & $* * *$ & 37.7 & 58.0 & $* * *$ \\
\hline Lives in imm enclave $(\%)$ & Lives in immigrant enclave & 23.9 & 25.5 & & 26.1 & 21.2 & $* * *$ \\
\hline
\end{tabular}

Note:

Weighted t-test performed. ${ }^{* * *} \mathrm{p}<0.001 ; * * \mathrm{p}<0.01 ; * \mathrm{p}<0.05$. Sources: NHTS 2009 and 2017. 


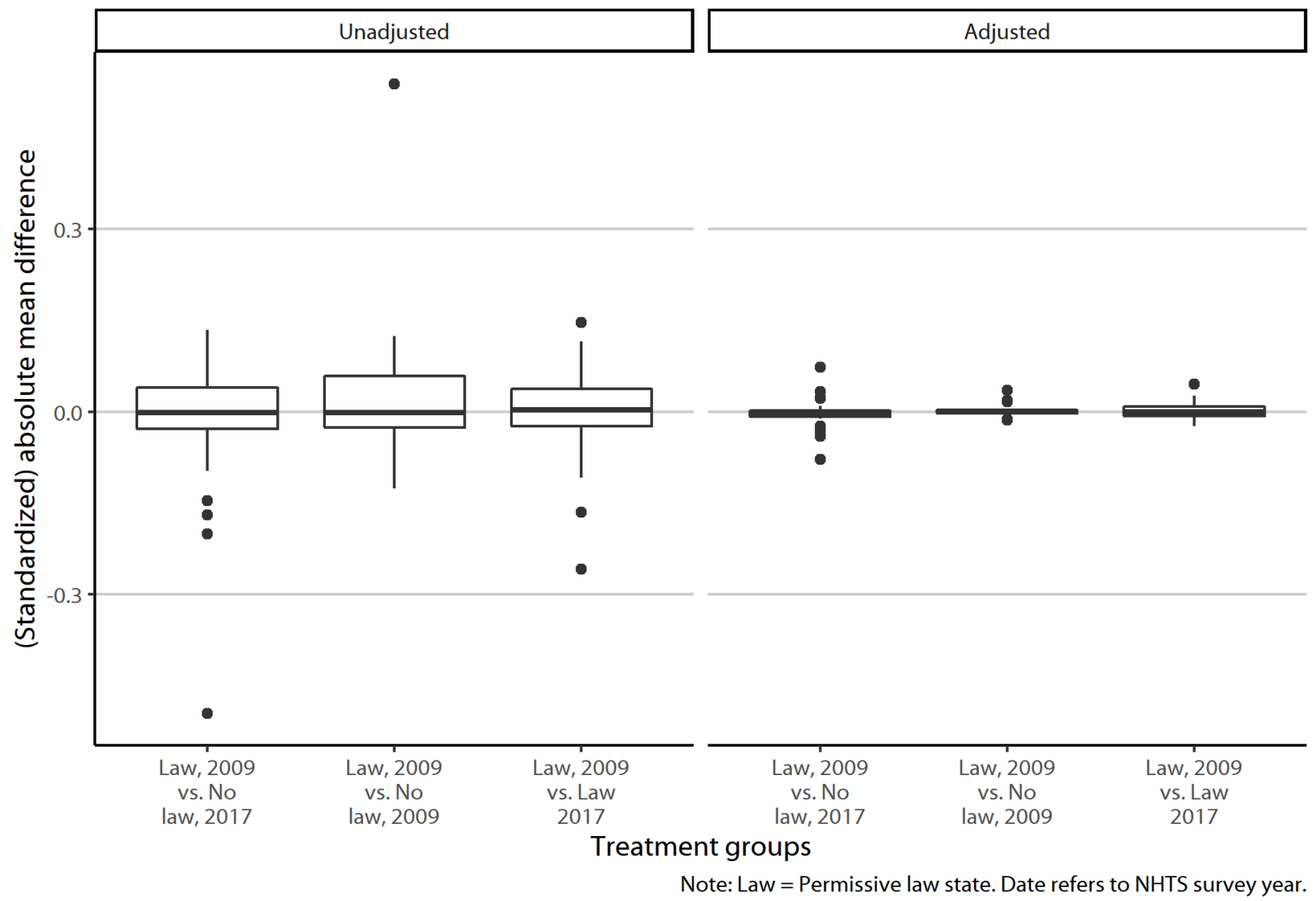

Figure 4: Distribution of (standardized) absolute mean differences in covariates, before and after propensity weighting. 
Each of the models is estimated on the same subset of the data and contains the same explanatory variables for consistency. This may result in models that are not optimally predictive, but it allows for easier interpretation of common effects across outcome variables. I used only the subset of data for immigrants to reduce model complexity, consistent with the hypothesis that permissive laws should have no effects on driving for US-born residents. I also excluded data from people who resided in Washington, Utah, and New Mexico. Those three states implemented permissive license laws before 2009 making it infeasible to identify a counterfactual with the data from the two travel surveys. All of the models were weighted using the propensity score weights. For VMT and trip counts, I estimated two forms of each model: a weighted model with the limited set of explanatory variables excluded from the propensity score weighting, and a weighted model with the full set of explanatory variables. Because propensity score weights already incorporate information about the explanatory variables, it is not strictly necessary to include them in a regression model. However, estimating a model with propensity score weights and the same covariates used in the weighting model leads to a doubly-robust model, which can compensate for misspecification in either the weighting model or the regression model (Lunceford and Davidian 2004). I estimated all models with robust standard errors clustered by state to account for unobserved correlation.

\subsubsection{Variable selection}

The doubly-robust models and weighting models included several personal and household factors expected to be associated with mode choice. For example, licensing rates among women are still lower than among men although the incidence reaches parity in younger age groups (Blumenberg et al. 2016). The disparity among foreign-born women is even greater, thus I expected to see a significant effect of gender in travel outcomes. Age is likely to have a quadratic effect, reflecting a lower likelihood of driving at both the youngest and oldest groups in the age spectrum, but higher during working age. Larger households would be expected to drive more often as transit is harder to navigate with multiple people in tow. I also expected people who hold jobs to drive more than the unemployed, and people with higher socioeconomic status reflected by higher educational attainment and household income were also expected to drive more. The model controls for race and ethnicity, though the expected direction of influence is unknown because other research findings are mixed on the effect of race and ethnicity on driving. Because mode choice assimilates to US-born patterns the longer immigrants live in the United States, the model controls for years since immigration for foreign-born individuals (Blumenberg 2009; Chatman and Klein 2009). The variable is log-transformed in the model reflecting the hypothesis that changes in behavior are more marked at early years of residence in the United States. Vehicle ownership is measured by the number of vehicles available per household driver. I also control for medical conditions that prevent driving and trip-making, as well as inflation-adjusted gas prices. Finally, while stricter immigration enforcement is likely to suppress mobility (see section 2.1), it is not feasible to adjust for enforcement activities nationwide in the model because of limited public information and the complex patchwork of federal, state, and local laws and policies.

The restricted-use data sets allowed for accurate measures of the built environment to be included in models. Population density and employment density are very highly correlated so I included only population density as a control. The proportion of people in poverty reflects the socioeconomic characteristics of the neighborhood, and urban size reflects both potential for interaction and necessity for relying on a vehicle. Research has found that immigrant enclaves are predictive of travel, reflecting an ease with which residents can take advantage of social ties to meet transportation needs (Blumenberg and Smart 2014; Shin 2017). In this study, I define an immigrant enclave as a census tract that has one-and-a-half the share of foreign-born residents as the county in which it is located. ${ }^{2}$

\section{Results}

This section describes the model results for each of the three research questions in the study. I present coefficient plots for the immigrant-related and policy variables in the main text; full model results are available in the appendix. On the whole, the implementation of permissive license laws had small effects on carpooling but no statistically distinguishable effects on driving alone.

\footnotetext{
${ }^{2}$ I also tested models where I included a continuous immigrant residential concentration quotient rather than a binary enclave variable. These models performed similarly to the enclave defintion described here.
} 


\subsection{Have permissive license laws affected personal VMT?}

Permissive licensing laws had no discernible effect on daily VMT among immigrants (Figure 5). In the covariate balanced-model, none of the three coefficients related to permissive licensing implementation (law, year, and the interaction term) were statistically significant. In other words, in states that passed permissive laws, VMT among immigrants would likely have been the same even if the state had not passed such legislation. Demographic control variables not included in the propensity score weighting conformed with expectations. A greater elapsed time since immigration was associated with more miles driven. The age coefficient was also positive and significant, while the quadratic age term was negative indicating that daily distance driven increases with age but peaks before declining as people get older. Consistent with expectations, living in an immigrant enclave was associated with fewer vehicle miles traveled; enclave residents drove about 0.3 fewer miles per day. Gas prices were insignificant, suggesting an inelastic relationship with driving once accounting for other covariates within the population weighting.

The doubly-robust model yielded the same patterns for the policy variables: permissive law state, survey year, and the difference-in-difference terms were all statistically insignificant. Signs and significance of the subset of control variables remained the same except for the immigrant enclave variable, which became insignificant. Once explicitly accounting for race/ethnicity, urban form variables, and other socioeconomic indicators, immigrants drove no more or less per day whether they lived in an enclave. The association was similar whether using a dichotomous variable for enclave status or a continuous variable for residential concentration. This finding is also consistent with other research that has found that controlling for socioeconomic and urban form variables reduces the explanatory power of an immigrant enclave variable (Chatman 2014). The fact that controlling for urban form controls changed the enclave coefficient is not unexpected because the initial propensity score weighting did not account for enclave residence.

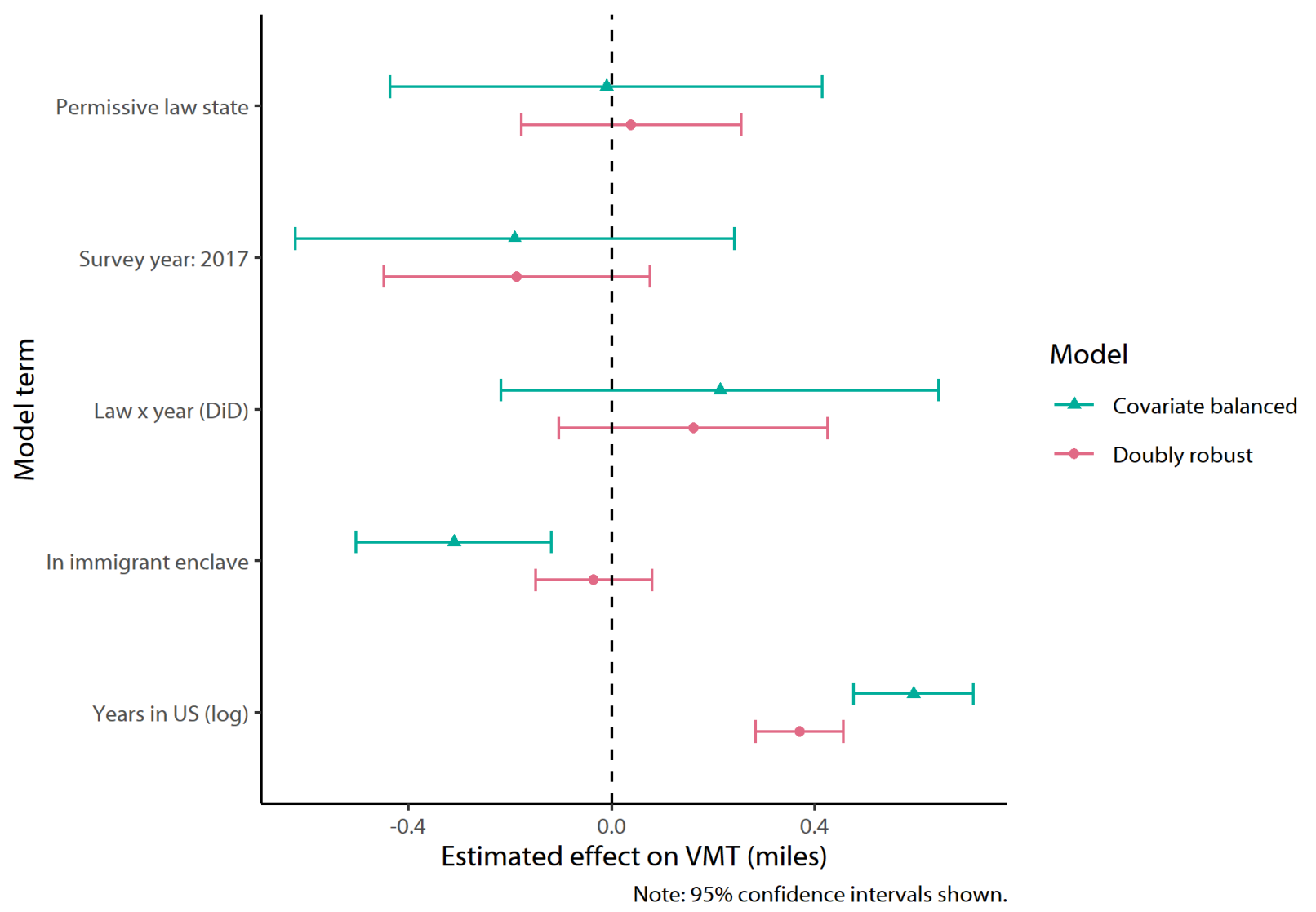

Figure 5: Estimated VMT model. Policy and immigrant-related coefficients shown. DiD $=$ difference-in-difference coefficient 


\subsection{Have permissive license laws affected the number of driving and carpooling trips?}

Relationships between licensing legislation and the count of trips driven yielded similar patterns as for VMT (Figure 6 , panel 1). While the survey year variable was statistically significant in this model, the policy variable was not. Immigrants drove about the same number of trips per day regardless of whether they lived in a permissive law state, but the rate of trip making by car was about $85 \%$ as much in 2017 as in $2009 .{ }^{3}$ The number of trips made in permissive law states would have been about the same regardless of whether the law had been passed. The influence of living in an immigrant enclave was significant; enclave residents drove at a rate about $9 \%$ less than non-enclave residents. As in the VMT model, length of residence in the US predicted more driving, while age followed the same quadratic pattern. Gas prices again did not significantly predict the number of trips driven. The doubly-robust model yielded similar patterns. There was no difference in the number of trips driven between permissive law states and other states, but immigrants drove fewer trips in 2017. The policy effects of permissive licensing are positively associated with driving rates but statistically insignificant. Adding the socioeconomic and urban form controls eliminated the effect of immigrant enclaves as in the VMT model.

In contrast to the number of trips driven, licensing laws appeared to increase the number of rides given, or the number of carpool trips in which the survey respondent was the driver (Figure 6, panel 2). Permissive license laws increased the rate of rides given by about $13 \%$, all else equal. The doubly-robust model yielded similar results, indicating a $12 \%$ increase in the rate of rides given. There was no difference across state grouping otherwise - that is, the license law variable was insignificant - but there was a decrease in the number of rides given between survey years, consistent with the previous models for trips taken. Living in an immigrant enclave did not predict a change in giving rides in either model specification.

Patterns for rides taken were less conclusive (Figure 6, panel 3). The minimal model again indicated a decline in carpooling between 2009 and 2017, whereas there was no difference across states with permissive laws and no difference after the law was passed when analyzed against the counterfactual case. The doubly-robust model had a marginally significant positive policy coefficient $(p=0.07)$. The model estimates that a permissive license law increased the carpooling rate by $6.5 \%$ after the laws were implemented. The effect of living in an immigrant enclave was insignificant in both model types.

\subsection{Have permissive license laws affected mode choice?}

Permissive license laws influenced mode switching across some modes (Figure 7). Estimates of minimal models had extremely poor fit, so I describe here only the fully-specified model. Coefficients were estimated relative to driving alone. The likelihood of carpooling remained unchanged after permissive law implementation relative to driving alone. Immigrants living in the group of ten permissive law states were already more likely to walk or cycle than those living elsewhere (RRR: 1.20, 95\% CI: 1.26-1.65), and the likelihood increased after law implementation. The model indicates a $44 \%$ increase in the relative risk (exponentiated logit) of nonmotorized trips. On the other hand, the policy term for transit was significant while the base difference between states was insignificant. Across all states, immigrants were more likely to take transit in 2017 than 2009 (RRR: 11.13, 95\% CI: 6.17-19.9), but introduction of a license law reduced this likelihood relative to driving alone (RRR: 0.14, 95\% CI: 0.089-0.21). In residential enclaves, immigrants were less likely to walk or cycle compared to driving alone (RRR: $1.10,95 \% \mathrm{CI}$ : $0.80-0.99$ ) but carpooling and transit use remained the same.

\section{Discussion and conclusion}

Historical data has shown that immigrants to the United States drive alone less than their US-born counterparts, relying on shared modes and walking for a greater share of their travel. This pattern holds true in the most recent travel data available. State-level policies in the form of legislation that permits undocumented immigrants to obtain drivers licenses appear to have some effects on travel as well. Covariate-balanced and adjusted difference-in-difference models indicated that immigrants both drive and ride in carpools slightly more frequently in permissive law states than they would have if the laws had not been passed. The permissive laws appeared to have minimal effects on distance traveled by car and frequency of driving alone; VMT and the total number of trips driven remained unchanged. Immigrants

\footnotetext{
${ }^{3}$ Per McGuckin and Fucci (2018), part of this difference may be an artifact of the change in survey methodology.
} 

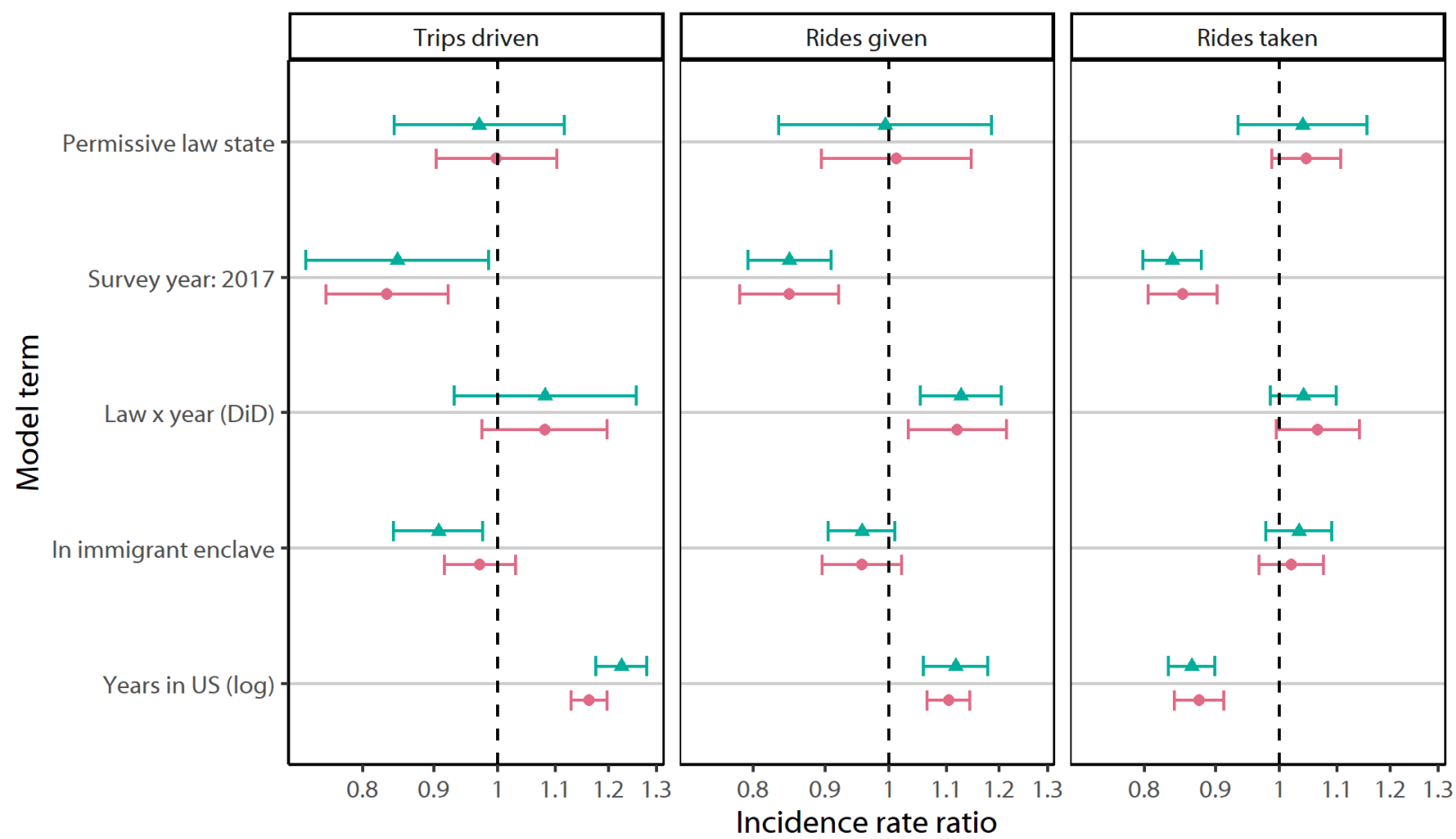

Model $\multimap$ Covariate balanced $\multimap$ Doubly robust

Note: $95 \%$ confidence intervals shown.

Figure 6: Estimated trips models. DiD = difference-in-difference coefficient 


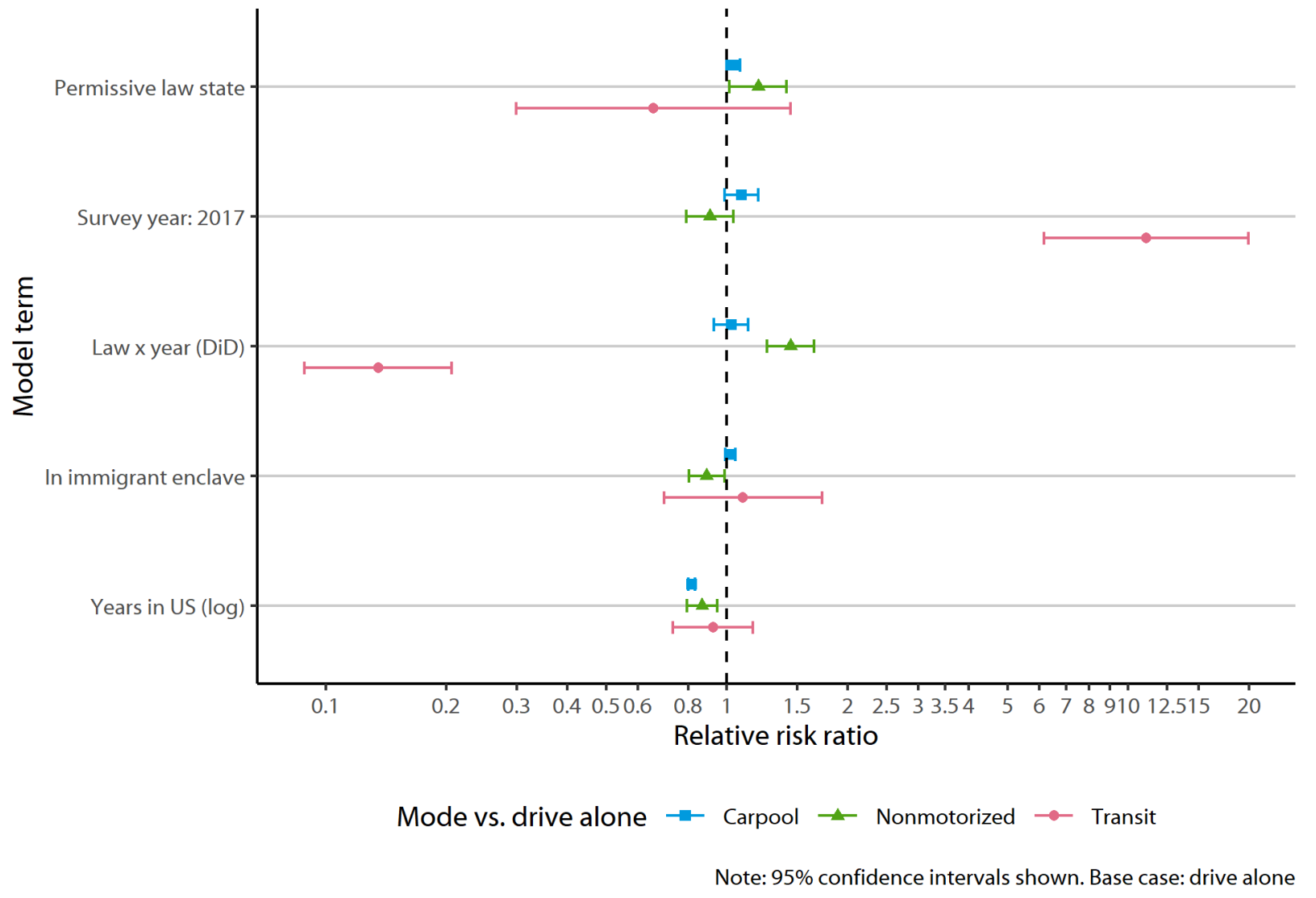

Figure 7: Mode choice models. DiD = difference-in-difference coefficient 
substituted driving alone for transit more than would be expected in the absence of a permissive law but also walked and cycled more. The significant findings are all the more surprising given that permissive laws directly affect only undocumented immigrants, who make up about a quarter of all foreign-born residents and whose numbers have been in decline since 2007 (Passel and Cohn 2018).

A few limitations to the study are important to mention. Legal status of immigration is not recorded in the National Household Travel Survey. It is not possible to estimate the laws' effects specifically for undocumented immigrants who are the direct beneficiaries of such laws. Most immigrants have legal status and so representation of the true effects of the legislation are dampened. It is likely that the estimates from the models presented in this study are the minimum effects of permissive licensing. It is also likely that undocumented immigrants are underrepresented in the dataset to begin with. They are less likely to respond to surveys and increasingly harder to reach during times of hostile political discourse such as during the time that the later wave of the NHTS was administered. Finally, NHTS methodology changed between survey waves. Although I modified values on the dataset to improve accuracy based on survey documentation (McGuckin and Fucci 2018), the adjustments are not perfect and introduce an additional source of error in model estimation.

The arguments against licensing undocumented immigrants are often political. Commentators bristle at extending a privilege to individuals whom they consider trespassers and law-breakers. Some officials have cited practical difficulties in issuing licenses, such as having to verify international identity documents with which Department of Motor Vehicles counter clerks may not be familiar (Tully and Gold 2019). Undocumented immigrants are not eligible for other rights that sometimes come with driver licensing, such as automatic voter registration, identification valid for air travel, and admittance to federal facilities, so administrative expenses may also increase in efforts to distinguish between two license types - one for undocumented immigrants and one for everyone else. But the denial of drivers licenses may cause more harm than good. Researchers estimated that the removal of driving privileges from undocumented immigrants in New Mexico would cost the state $\$ 38.5$ million in economic productivity per year in the short run (Rubalcaba and Juárez 2016). In Oregon, the figure was $\$ 160$ million, or $0.1 \%$ of the state's GDP, from labor contraction in agriculture, construction, and food service, where most undocumented immigrants worked (King et al. 2011). Spending on vehicles and vehicle-related services are also lower when undocumented immigrants cannot obtain licenses.

This study adds additional supportive evidence for wider adoption of permissive licensing laws. The primary increase in car use takes the form of carpooling rather than additional drive alone trips and did not appear to reduce the likelihood of using active transportation. This suggests that even though even though legislation adds new licensed drivers to the roadways, it may not detract from other planning goals such as increasing sustainable transportation. In fact, permissive licensing improves access to opportunities for undocumented immigrants and creates more equitable transportation conditions. About one in six carpool trips were made with additional household members, many of whom are citizenor resident-children of immigrants, meaning that the mobility benefits of licensing accrue to those not directly affected by the laws. Further, communities that rely on sharing vehicles and rides as immigrants tend to do have lower levels of isolation and exclusion that come with a lack of vehicle access (Stuesse and Coleman 2014). States would do well to conduct their own policy analyses relative to safety improvements, economic impacts, and mobility benefits. Positive benefits may help advocates sway public and political opinion in favor of adopting permissive licensing laws.

Funding: This research did not receive any specific grant from funding agencies in the public, commercial, or not-forprofit sectors. 


\section{References}

Allen, Ryan, and Jueyu Wang. 2020. "Immigrant Legal Status and Commute Mode Choice for Hispanics in the United States." Journal of the American Planning Association 0 (0): 1-13. https://doi.org/10.1080/01944363.2020.1724 818.

Bachmeier, James D., Jennifer Van Hook, and Frank D. Bean. 2014. “Can We Measure Immigrants' Legal Status? Lessons from Two U.S. Surveys.” International Migration Review 48 (2): 538-66. https://doi.org/10.1111/imre.1 2059.

Barajas, Jesus M. 2020. "Supplemental Infrastructure: How Community Networks and Immigrant Identity Influence Cycling.” Transportation 47: 1251-74. https://doi.org/10.1007/s11116-018-9955-7.

Blumenberg, Evelyn. 2009. "Moving in and Moving Around: Immigrants, Travel Behavior, and Implications for Transport Policy." Transportation Letters: The International Journal of Transportation Research 1: 169-80. https: //doi.org/10.3328/TL.2009.01.02.169-180.

2016. "Why Low-Income Women in the US Still Need Automobiles." Town Planning Review 87 (5): 525-45. https://doi.org/10.3828/tpr.2016.34.

Blumenberg, Evelyn, Kelcie Ralph, Michael Smart, and Brian D. Taylor. 2016. "Who Knows about Kids These Days? Analyzing the Determinants of Youth and Adult Mobility in the U.S. Between 1990 and 2009." Transportation Research Part A: Policy and Practice 93 (November): 39-54. https://doi.org/10.1016/j.tra.2016.08.010.

Blumenberg, Evelyn, and Michael Smart. 2010. "Getting by with a Little Help from My Friends...and Family: Immigrants and Carpooling." Transportation 37: 429-46. https://doi.org/10.1007/s11116-010-9262-4.

_. 2014. "Brother Can You Spare a Ride? Carpooling in Immigrant Neighbourhoods." Urban Studies 51 (9): 1871-90. https://doi.org/10.1177/0042098013502825.

Bohon, Stephanie A., Katherine Stamps, and Jorge H. Atiles. 2008. "Transportation and Migrant Adjustment in Georgia." Population Research and Policy Review 27 (3): 273-91. https://doi.org/10.1007/s11113-008-9075-8.

Cao, Xinyu (Jason), and Dean Porter-Nelson. 2016. "Real Estate Development in Anticipation of the Green Line Light Rail Transit in St. Paul." Transport Policy 51 (October): 24-32. https://doi.org/10.1016/j.tranpol.2016.01.007.

Cáceres, Mauricio, and Kenneth P. Jameson. 2015. "The Effects on Insurance Costs of Restricting Undocumented Immigrants' Access to Driver Licenses.” Southern Economic Journal 81 (4): 907-27. https://doi.org/10.1002/so ej.12022.

Cervero, Robert, Onésimo Sandoval, and John Landis. 2002. "Transportation as a Stimulus of Welfare-to-Work: Private Versus Public Mobility.” Journal of Planning Education and Research 22 (1): 50-63. https://doi.org/10.1 177/0739456X0202200105.

Chatman, Daniel G. 2014. "Explaining the "Immigrant Effect" on Auto Use: The Influences of Neighborhoods and Preferences." Transportation 41 (3): 441-61. https://doi.org/10.1007/s11116-013-9475-4.

Chatman, Daniel G., and Nicholas Klein. 2009. "Immigrants and Travel Demand in the United States: Implications for Transportation Policy and Future Research." Public Works Management \& Policy 13 (4): 312-27. https: //doi.org/10.1177/1087724X09334633.

2011. "Immigrants and Automobility in New Jersey: The Role of Spatial and Occupational Factors in Commuting to Work." In Auto Motives: Understanding Car Use, edited by Karen Lucas, Evelyn Blumenberg, and Rachel Weinberger, 253-76. Bingley, UK: Emerald Group Publishing.

Chatman, Daniel G., and Nicholas J. Klein. 2013. "Why Do Immigrants Drive Less? Confirmations, Complications, and New Hypotheses from a Qualitative Study In New Jersey, USA.” Transport Policy 30: 336-44. https://doi.or $\mathrm{g} / 10.1016 / \mathrm{j}$.tranpol.2013.10.002.

Dill, Jennifer, Nathan McNeil, Joseph Broach, and Liang Ma. 2014. "Bicycle Boulevards and Changes in Physical Activity and Active Transportation: Findings from a Natural Experiment." Preventive Medicine, Supplement: Active Living Research - Niche to Norm, 69 (December): S74-78. https://doi.org/10.1016/j.ypmed.2014.10.006. 
Frey, William H. 2018. "Early Decade Big City Growth Continues to Fall Off, Census Shows." Brookings. May 25, 2018. https://www.brookings.edu/blog/the-avenue/2018/05/25/early-decade-big-city-growth-continues-to-falloff-census-shows/.

Gallego, Francisco, Juan-Pablo Montero, and Christian Salas. 2013. "The Effect of Transport Policies on Car Use: Evidence from Latin American Cities.” Journal of Public Economics 107 (November): 47-62. https://doi.org/10 .1016/j.jpubeco.2013.08.007.

Gelman, Andrew, and Jennifer Hill. 2007. Data Analysis Using Regression and Multilevel/Hierarchical Models. Analytical Methods for Social Research. Cambridge ; New York: Cambridge University Press.

Gonzales, Roberto G., Veronica Terriquez, and Stephen P. Ruszczyk. 2014. "Becoming DACAmented: Assessing the Short-Term Benefits of Deferred Action for Childhood Arrivals (DACA)." American Behavioral Scientist 58 (14): 1852-72. https://doi.org/10.1177/0002764214550288.

Grengs, Joe. 2010. "Job Accessibility and the Modal Mismatch in Detroit." Journal of Transport Geography 18 (1): 42-54. https://doi.org/10.1016/j.jtrangeo.2009.01.012.

. 2012. "Equity and the Social Distribution of Job Accessibility in Detroit." Environment and Planning B: Planning and Design 39 (5): 785-800. https://doi.org/10.1068/b36097.

Griefer, Noah. 2019a. "Cobalt: Covariance Balance Tables and Plots." https://CRAN.R-project.org/package=cobalt.

_. 2019b. "WeightIt: Weighting for Covariate Balance in Observational Studies." https://CRAN.R-project.org/ package $=$ WeightIt.

King, Mary C, John G Corbett, John Chiappetta, and Anabel López Salinas. 2011. "Assessment of the Socio-Economic Impacts of SB 1080 on Immigrant Groups.” SR 500-270. Portland, OR: Portland State University. https://pdxsch olar.library.pdx.edu/cgi/viewcontent.cgi?article $=1042 \&$ context $=$ econ_fac.

Liu, Cathy Yang, and Gary Painter. 2012. "Travel Behavior Among Latino Immigrants: The Role of Ethnic Concentration and Ethnic Employment." Journal of Planning Education and Research 32 (1): 62-80. https://doi.org/10 $.1177 / 0739456 X 11422070$.

Lovejoy, Kristin, and Susan Handy. 2008. "A Case for Measuring Individuals' Access to Private-Vehicle Travel as a Matter of Degrees: Lessons from Focus Groups with Mexican Immigrants in California." Transportation 35 (5): 601-12. https://doi.org/10.1007/s11116-008-9169-5.

— 2011. "Social Networks As a Source of Private-Vehicle Transportation: The Practice of Getting Rides and Borrowing Vehicles Among Mexican Immigrants in California." Transportation Research Part A: Policy and Practice 45 (4): 248-57. https://doi.org/10.1016/j.tra.2011.01.007.

Lueders, Hans, Jens Hainmueller, and Duncan Lawrence. 2017. "Providing Driver's Licenses to Unauthorized Immigrants in California Improves Traffic Safety." Proceedings of the National Academy of Sciences 114 (16): 4111-16. https://doi.org/10.1073/pnas.1618991114.

Lunceford, Jared K., and Marie Davidian. 2004. "Stratification and Weighting via the Propensity Score in Estimation of Causal Treatment Effects: A Comparative Study.” Statistics in Medicine 23 (19): 2937-60. https://doi.org/10.1 002/sim.1903.

McDonald, John F., and Robert A. Moffitt. 1980. "The Uses of Tobit Analysis." The Review of Economics and Statistics 62 (2): 318-21. https://doi.org/10.2307/1924766.

McGuckin, Nancy, and A. Fucci. 2018. "Summary of Travel Trends: 2017 National Household Travel Survey." Washington, D.C.: Federal Highway Administration.

National Conference of State Legislatures. 2020. "States Offering Driver's Licenses to Immigrants." February 6, 2020. http://www.ncsl.org/research/immigration/states-offering-driver-s-licenses-to-immigrants.aspx.

Ong, Paul M. 2002. "Car Ownership and Welfare-to-Work." Journal of Policy Analysis and Management 21 (2): 239-52. https://doi.org/10.1002/pam.10025. 
Passel, Jeffrey S., and D’Vera Cohn. 2018. "U.S. Unauthorized Immigrant Total Dips to Lowest Level in a Decade." Washington, D.C.: Pew Research Center. https://www.pewresearch.org/hispanic/2018/11/27/u-s-unauthorizedimmigrant-total-dips-to-lowest-level-in-a-decade/.

Rosenbaum, Paul R., and Donald B. Rubin. 1983. "The Central Role of the Propensity Score in Observational Studies for Causal Effects." Biometrika 70 (1): 41-55. https://doi.org/10.1093/biomet/70.1.41.

Rubalcaba, Joaquín Alfredo-Angel, and Melinda Juárez. 2016. "The Economic Costs Associated With the Removal of Driver's Licenses for Undocumented Immigrants in New Mexico." Albuquerque: University of New Mexico. http://healthpolicy.unm.edu/node/1037023.

Shin, Eun Jin. 2017. "Unraveling the Effects of Residence in an Ethnic Enclave on Immigrants' Travel Mode Choices." Journal of Planning Education and Research 37 (4): 425-43. https://doi.org/10.1177/0739456X16663309.

Smart, Michael J. 2015. “A Nationwide Look at the Immigrant Neighborhood Effect on Travel Mode Choice.” Transportation 42 (1): 189-209. https://doi.org/10.1007/s11116-014-9543-4.

Snyder, Anne. 2015. "To the Suburbs!: Lessons from Minorities and the New Immigrants.” In America's Housing Crisis, 68-81. Chapman University Press. https://opportunityurbanism.org/wp-content/uploads/2016/10/COUHousing-Crisis-Report.pdf.

Stuart, Elizabeth A. 2010. "Matching Methods for Causal Inference: A Review and a Look Forward." Statistical Science 25 (1): 1-21. https://doi.org/10.1214/09-STS313.

Stuart, Elizabeth A., Haiden A. Huskamp, Kenneth Duckworth, Jeffrey Simmons, Zirui Song, Michael Chernew, and Colleen L. Barry. 2014. "Using Propensity Scores in Difference-in-Differences Models to Estimate the Effects of a Policy Change." Health Services \& Outcomes Research Methodology 14 (4): 166-82. https://doi.org/10.1007/ s10742-014-0123-z.

Stuesse, Angela, and Mathew Coleman. 2014. "Automobility, Immobility, Altermobility: Surviving and Resisting the Intensification of Immigrant Policing.” City \& Society 26 (1): 51-72. https://doi.org/10.1111/ciso.12034.

Tal, Gil, and Susan Handy. 2010. "Travel Behavior of Immigrants: An Analysis of the 2001 National Household Transportation Survey.” Transport Policy 17 (2): 85-93. https://doi.org/10.1016/j.tranpol.2009.11.003.

Toomey, Russell B., Adriana J. Umaña-Taylor, David R. Williams, Elizabeth Harvey-Mendoza, Laudan B. Jahromi, and Kimberly A. Updegraff. 2014. "Impact of Arizona's SB 1070 Immigration Law on Utilization of Health Care and Public Assistance Among Mexican-Origin Adolescent Mothers and Their Mother Figures." American Journal of Public Health 104 (S1): S28-34. https://doi.org/10.2105/AJPH.2013.301655.

Tully, Tracey, and Michael Gold. 2019. "Long Lines as Undocumented Immigrants in N.Y. Rush to Get Licenses." The New York Times: New York, December 16, 2019. https://www.nytimes.com/2019/12/16/nyregion/undocumentedimmigrant-drivers-license-ny-nj.html.

U. S. Census Bureau. 2010. “American Community Survey 1-Year Estimates: 2009.” https://data.census.gov/. . 2018. “American Community Survey 1-Year Estimates: 2017.” https://data.census.gov.

Wilson, Jill H., and Nicole Prchal Svajlenka. 2014. "Immigrants Continue to Disperse, with Fastest Growth in the Suburbs.” Brookings. October 29, 2014. https://www.brookings.edu/research/immigrants-continue-to-dispersewith-fastest-growth-in-the-suburbs/.

Wines, Michael, and Jose A. Del Real. 2019. "In 2020 Census, Big Efforts in Some States. In Others, Not So Much." The New York Times: U.S., December 15, 2019. https://www.nytimes.com/2019/12/15/us/census-california-texasundercount.html.

Wing, Coady, Kosali Simon, and Ricardo A. Bello-Gomez. 2018. "Designing Difference in Difference Studies: Best Practices for Public Health Policy Research.” Annual Review of Public Health 39 (1): 453-69. https://doi.org/10 .1146/annurev-publhealth-040617-013507. 
A Appendix: Full regression model estimates 


\begin{tabular}{|c|c|c|}
\hline & Cov. balanced & Doubly robust \\
\hline Permissive law state & $-0.01(0.22)$ & $0.04(0.11)$ \\
\hline Survey year: 2017 & $-0.19(0.22)$ & $-0.19(0.13)$ \\
\hline Law x year (DiD) & $0.21(0.22)$ & $0.16(0.14)$ \\
\hline Years in US (log) & $0.59(0.06)^{* * *}$ & $0.37(0.04)^{* * *}$ \\
\hline Age & $0.19(0.01)^{* * *}$ & $0.09(0.01)^{* * *}$ \\
\hline $\mathrm{Age}^{2}$ & $-0.00(0.00)^{* * *}$ & $-0.00(0.00)^{* * *}$ \\
\hline Immigrant enclave & $-0.31(0.10)^{* *}$ & $-0.04(0.06)$ \\
\hline Gas price (2017 cents) & $-0.00(0.00)$ & $-0.00(0.00)$ \\
\hline Female & & $-0.82(0.07)^{* * *}$ \\
\hline Num. children & & $0.07(0.01)^{* * *}$ \\
\hline Cars per driver & & $0.55(0.14)^{* * *}$ \\
\hline Race: Black & & $0.08(0.05)$ \\
\hline Race: Latino & & $0.10(0.05)^{*}$ \\
\hline Race: Asian & & $0.02(0.03)$ \\
\hline Race: Other & & $-0.15(0.07)^{*}$ \\
\hline Income: Quintile 2 & & $0.14(0.05)^{* *}$ \\
\hline Income: Quintile 3 & & $0.12(0.07)$ \\
\hline Income: Quintile 4 & & $0.06(0.05)$ \\
\hline Income: Quintile 5 & & $-0.02(0.05)$ \\
\hline Income: Missing & & $-0.05(0.07)$ \\
\hline Employed & & $0.77(0.04)^{* * *}$ \\
\hline Renter & & $-0.36(0.07)^{* * *}$ \\
\hline Education: High school & & $0.83(0.09)^{* * *}$ \\
\hline Education: College & & $0.97(0.07)^{* * *}$ \\
\hline Education: In school & & $-1.71(0.15)^{* * *}$ \\
\hline Education: Missing & & $-0.24(0.21)$ \\
\hline Medical cond. limits driving & & $-3.66(0.26)^{* * *}$ \\
\hline Medical cond. limits travel & & $-0.24(0.05)^{* * *}$ \\
\hline Tract \% poverty $(\log )$ & & $-0.97(0.21)^{* * *}$ \\
\hline Tract pop. density (log, per km²) & & $-0.28(0.11)^{*}$ \\
\hline Urban size: $50,000-199,999$ & & $0.28(0.20)$ \\
\hline Urban size: 200,000-499,999 & & $0.39(0.20)$ \\
\hline Urban size: 500,000-999,999 & & $0.44(0.22)$ \\
\hline Urban size: 1 million+, no heavy rail & & $0.64(0.29)^{*}$ \\
\hline Urban size: 1 million+, heavy rail & & $0.28(0.23)$ \\
\hline Intercept & $-3.70(0.24)^{* * *}$ & $-0.78(0.65)$ \\
\hline AIC & 97041.19 & 90019.85 \\
\hline Log Likelihood & -48510.60 & -44972.93 \\
\hline Deviance & 48801.12 & 47036.62 \\
\hline Total & 40631 & 40631 \\
\hline Left-censored & 11792 & 11792 \\
\hline Uncensored & 28839 & 28839 \\
\hline Right-censored & 0 & 0 \\
\hline
\end{tabular}

Table 2: Tobit regression models of daily VMT 


\begin{tabular}{|c|c|c|c|c|c|c|}
\hline & Trips driven (CB) & Trips driven (DR) & Rides given (CB) & Rides given (DR) & Rides taken $(\mathrm{CB})$ & Rides taken (DR) \\
\hline Permissive law state & $-0.03(0.07)$ & $-0.00(0.05)$ & $-0.01(0.09)$ & $0.01(0.06)$ & $0.04(0.05)$ & $0.04(0.03)$ \\
\hline Survey year: 2017 & $-0.17(0.08)^{*}$ & $-0.18(0.05)^{* * *}$ & $-0.16(0.04)^{* * *}$ & $-0.16(0.04)^{* * *}$ & $-0.18(0.02)^{* * *}$ & $-0.16(0.03)^{* * *}$ \\
\hline Law x year (DiD) & $0.08(0.08)$ & $0.08(0.05)$ & $0.12(0.03)^{* * *}$ & $0.11(0.04)^{* *}$ & $0.04(0.03)$ & $0.06(0.03)$ \\
\hline Years in US $(\log )$ & $0.20(0.02)^{* * *}$ & $0.15(0.01)^{* * *}$ & $0.11(0.03)^{* * *}$ & $0.10(0.02)^{* * *}$ & $-0.15(0.02)^{* * *}$ & $-0.13(0.02)^{* * *}$ \\
\hline Age & $0.08(0.00)^{* * *}$ & $0.04(0.00)^{* * *}$ & $0.08(0.01)^{* * *}$ & $0.06(0.01)^{* * *}$ & $-0.07(0.01)^{* * *}$ & $-0.05(0.01)^{* * *}$ \\
\hline $\mathrm{Age}^{2}$ & $-0.00(0.00)^{* * *}$ & $-0.00(0.00)^{* * *}$ & $-0.00(0.00)^{* * *}$ & $-0.00(0.00)^{* * *}$ & $0.00(0.00)^{* * *}$ & $0.00(0.00)^{* * *}$ \\
\hline Immigrant enclave & $-0.10(0.04)^{* *}$ & $-0.03(0.03)$ & $-0.04(0.03)$ & $-0.04(0.03)$ & $0.03(0.03)$ & $0.02(0.03)$ \\
\hline Gas price (2017 cents) & $-0.00(0.00)$ & $-0.00(0.00)^{*}$ & $-0.00(0.00)$ & $0.00(0.00)$ & $0.00(0.00)$ & $-0.00(0.00)$ \\
\hline Female & & $-0.21(0.03)^{* * *}$ & & $-0.41(0.04)^{* * *}$ & & $0.96(0.03)^{* * *}$ \\
\hline Num. children & & $0.09(0.01)^{* * *}$ & & $0.28(0.01)^{* * *}$ & & $-0.03(0.01)^{*}$ \\
\hline Cars per driver & & $0.25(0.05)^{* * *}$ & & $0.18(0.06)^{* *}$ & & $-0.02(0.07)$ \\
\hline Race: Black & & $0.03(0.05)$ & & $0.02(0.10)$ & & $-0.08(0.09)$ \\
\hline Race: Latino & & $0.06(0.01)^{* * *}$ & & $0.21(0.03)^{* * *}$ & & $0.08(0.02)^{* * *}$ \\
\hline Race: Asian & & $-0.05(0.01)^{* * *}$ & & $0.04(0.03)$ & & $0.01(0.04)$ \\
\hline Race: Other & & $-0.08(0.03)^{*}$ & & $0.00(0.06)$ & & $0.12(0.06)^{*}$ \\
\hline Income: Quintile 2 & & $0.06(0.03)^{*}$ & & $0.08(0.05)$ & & $0.09(0.06)$ \\
\hline Income: Quintile 3 & & $0.04(0.04)$ & & $0.02(0.06)$ & & $0.16(0.03)^{* * *}$ \\
\hline Income: Quintile 4 & & $0.01(0.03)$ & & $0.01(0.02)$ & & $0.17(0.02)^{* * *}$ \\
\hline Income: Quintile 5 & & $-0.01(0.03)$ & & $0.01(0.04)$ & & $0.23(0.03)^{* * *}$ \\
\hline Income: Missing & & $-0.09(0.03)^{* *}$ & & $-0.11(0.04)^{* *}$ & & $0.14(0.09)$ \\
\hline Employed & & $0.09(0.02)^{* * *}$ & & $-0.27(0.03)^{* * *}$ & & $-0.42(0.04)^{* * *}$ \\
\hline Renter & & $-0.07(0.03)^{*}$ & & $-0.03(0.04)$ & & $-0.05(0.03)$ \\
\hline Education: High school & & $0.41(0.04)^{* * *}$ & & $0.40(0.05)^{* * *}$ & & $-0.19(0.03)^{* * *}$ \\
\hline Education: College & & $0.49(0.04)^{* * *}$ & & $0.57(0.04)^{* * *}$ & & $-0.26(0.05)^{* * *}$ \\
\hline Education: In school & & $-1.46(0.13)^{* * *}$ & & $-1.93(0.18)^{* * *}$ & & $0.17(0.12)$ \\
\hline Education: Missing & & $-0.16(0.10)$ & & $-0.32(0.12)^{* *}$ & & $0.00(0.10)$ \\
\hline Medical cond. limits driving & & $-3.14(0.15)^{* * *}$ & & $-4.03(0.62)^{* * *}$ & & $0.60(0.07)^{* * *}$ \\
\hline Medical cond. limits travel & & $-0.14(0.03)^{* * *}$ & & $-0.20(0.06)^{* *}$ & & $0.16(0.04)^{* * *}$ \\
\hline Tract $\%$ poverty $(\log )$ & & $-0.13(0.18)$ & & $0.15(0.27)$ & & $0.47(0.14)^{* * *}$ \\
\hline Tract pop. density $\left(\log\right.$, per $\left.\mathrm{km}^{2}\right)$ & & $-0.09(0.05)$ & & $-0.08(0.05)$ & & $-0.09(0.03)^{* *}$ \\
\hline Urban size: $50,000-199,999$ & & $0.23(0.10)^{*}$ & & $0.16(0.11)$ & & $0.11(0.06)$ \\
\hline Urban size: $200,000-499,999$ & & $0.21(0.10)^{*}$ & & $0.20(0.07)^{* *}$ & & $0.06(0.09)$ \\
\hline Urban size: $500,000-999,999$ & & $0.24(0.10)^{*}$ & & $0.17(0.10)$ & & $0.12(0.09)$ \\
\hline Urban size: 1 million+, no heavy rail & & $0.28(0.13)^{*}$ & & $0.21(0.13)$ & & $0.07(0.08)$ \\
\hline Urban size: 1 million+, heavy rail & & $0.11(0.11)$ & & $0.03(0.12)$ & & $-0.03(0.07)$ \\
\hline Intercept & $-1.11(0.09)^{* * *}$ & $-0.56(0.28)^{*}$ & $-1.94(0.15)^{* * *}$ & $-1.73(0.37)^{* * *}$ & $1.65(0.17)^{* * *}$ & $1.50(0.27)^{* * *}$ \\
\hline AIC & 117645.64 & 113552.51 & 73968.76 & 72208.91 & 59669.46 & 58119.34 \\
\hline Log Likelihood & -58812.82 & -56739.26 & -36974.38 & -36067.46 & -29824.73 & -29022.67 \\
\hline Deviance & 33386.28 & 33059.64 & 21798.14 & 21907.81 & 17388.30 & 17789.86 \\
\hline Num. obs. & 41780 & 41780 & 41780 & 41780 & 41780 & 41780 \\
\hline
\end{tabular}

Base levels: Race: White; Income: Quintile 1; Education: Less than high school; Urban size: Not in an urban area

Table 3: Negative binomial models of trip taking 


\begin{tabular}{|c|c|c|c|c|}
\hline & Carpool & Nonmotorized & Transit & Other \\
\hline Permissive law state & $0.04(0.02)$ & $0.18(0.08)^{*}$ & $-0.42(0.40)$ & $0.89(0.52)$ \\
\hline Survey year: 2017 & $0.08(0.05)$ & $-0.10(0.07)$ & $2.41(0.30)^{* * *}$ & $0.20(0.70)$ \\
\hline Law x year (DiD) & $0.03(0.05)$ & $0.36(0.07)^{* * *}$ & $-2.00(0.21)^{* * *}$ & $-1.35(0.66)^{*}$ \\
\hline Years in US $(\log )$ & $-0.20(0.01)^{* * *}$ & $-0.14(0.04)^{* *}$ & $-0.08(0.12)$ & $-1.68(0.15)^{* * *}$ \\
\hline Age & $-0.03(0.00)^{* * *}$ & $0.04(0.01)^{* * *}$ & $0.03(0.03)$ & $-0.66(0.04)^{* * *}$ \\
\hline $\mathrm{Age}^{2}$ & $0.00(0.00)^{* * *}$ & $-0.00(0.00)^{* * *}$ & $-0.00(0.00)$ & $0.01(0.00)^{* * *}$ \\
\hline Immigrant enclave & $0.02(0.01)$ & $-0.12(0.05)^{*}$ & $0.09(0.23)$ & $0.73(0.33)^{*}$ \\
\hline Gas price (2017 cents) & $0.00(0.00)^{* * *}$ & $0.00(0.00)$ & $0.00(0.00)$ & $-0.00(0.00)$ \\
\hline Female & $0.28(0.02)^{* * *}$ & $-0.03(0.03)$ & $1.54(0.17)^{* * *}$ & $0.28(0.16)$ \\
\hline Num. children & $0.21(0.01)^{* * *}$ & $-0.21(0.03)^{* * *}$ & $0.07(0.06)$ & $1.69(0.12)^{* * *}$ \\
\hline Cars per driver & $-0.26(0.02)^{* * *}$ & $0.30(0.05)^{* * *}$ & $-12.45(0.21)^{* * *}$ & $1.98(0.23)^{* * *}$ \\
\hline Race: Black & $0.02(0.09)$ & $-1.48(0.29)^{* * *}$ & $1.51(0.82)$ & $7.19(1.39)^{* * *}$ \\
\hline Race: Latino & $0.18(0.02)^{* * *}$ & $-0.83(0.05)^{* * *}$ & $1.37(0.23)^{* * *}$ & $3.51(0.39)^{* * *}$ \\
\hline Race: Asian & $0.18(0.03)^{* * *}$ & $-0.39(0.05)^{* * *}$ & $0.66(0.21)^{* *}$ & $1.71(0.38)^{* * *}$ \\
\hline Race: Other & $0.17(0.03)^{* * *}$ & $-0.44(0.07)^{* * *}$ & $1.62(0.16)^{* * *}$ & $1.67(0.63)^{* *}$ \\
\hline Income: Quintile 2 & $0.09(0.02)^{* * *}$ & $0.08(0.06)$ & $-1.08(0.48)^{*}$ & $-0.14(0.20)$ \\
\hline Income: Quintile 3 & $0.12(0.02)^{* * *}$ & $0.46(0.08)^{* * *}$ & $-1.80(0.29)^{* * *}$ & $-2.00(0.65)^{* *}$ \\
\hline Income: Quintile 4 & $0.18(0.03)^{* * *}$ & $0.35(0.11)^{* *}$ & $-1.57(0.60)^{* *}$ & $-0.47(0.61)$ \\
\hline Income: Quintile 5 & $0.25(0.02)^{* * *}$ & $0.31(0.11)^{* *}$ & $-0.63(0.31)^{*}$ & $1.16(0.82)$ \\
\hline Employed & $-0.68(0.02)^{* * *}$ & $-0.66(0.05)^{* * *}$ & $1.29(0.27)^{* * *}$ & $-4.35(0.39)^{* * *}$ \\
\hline Renter & $0.10(0.01)^{* * *}$ & $-0.08(0.08)$ & $1.34(0.21)^{* * *}$ & $2.18(0.32)^{* * *}$ \\
\hline Education: High school & $-0.33(0.02)^{* * *}$ & $0.05(0.09)$ & $-0.62(0.27)^{*}$ & $-4.17(0.37)^{* * *}$ \\
\hline Education: College & $-0.31(0.02)^{* * *}$ & $0.54(0.17)^{* *}$ & $-1.39(0.38)^{* * *}$ & $-6.01(0.74)^{* * *}$ \\
\hline Education: In school & $0.94(0.14)^{* * *}$ & $0.82(0.36)^{*}$ & $2.84(1.95)$ & $-2.58(0.75)^{* * *}$ \\
\hline Medical cond. limits driving & $2.71(0.07)^{* * *}$ & $1.83(0.23)^{* * *}$ & $3.83(0.49)^{* * *}$ & $6.06(0.53)^{* * *}$ \\
\hline Medical cond. limits travel & $0.07(0.03)^{*}$ & $-0.25(0.09)^{* *}$ & $-1.02(0.22)^{* * *}$ & $2.20(0.55)^{* * *}$ \\
\hline Tract $\%$ poverty $(\log )$ & $0.57(0.09)^{* * *}$ & $2.10(0.24)^{* * *}$ & $0.18(1.18)$ & $-10.57(1.45)^{* * *}$ \\
\hline Tract pop. density (log, per $\mathrm{km}^{2}$ ) & $0.01(0.01)$ & $0.02(0.03)$ & $2.97(0.07)^{* * *}$ & $-0.58(0.08)^{* * *}$ \\
\hline Urban size: $50,000-199,999$ & $-0.18(0.06)^{* *}$ & $-0.40(0.17)^{*}$ & $-1.39(0.78)$ & $0.28(0.92)$ \\
\hline Urban size: $200,000-499,999$ & $-0.10(0.03)^{* * *}$ & $-0.63(0.17)^{* * *}$ & $-0.83(0.57)$ & $2.42(0.47)^{* * *}$ \\
\hline Urban size: $500,000-999,999$ & $-0.17(0.05)^{* *}$ & $-0.34(0.22)$ & $-2.55(1.42)$ & $0.81(0.97)$ \\
\hline Urban size: 1 million+, no heavy rail & $-0.19(0.04)^{* * *}$ & $-0.41(0.11)^{* * *}$ & $-3.21(0.48)^{* * *}$ & $1.28(0.44)^{* *}$ \\
\hline Urban size: 1 million+, heavy rail & $-0.15(0.05)^{* *}$ & $-0.16(0.09)$ & $-1.02(0.67)$ & $0.34(0.51)$ \\
\hline Intercept & $1.64(0.09)^{* * *}$ & $-4.60(0.46)^{* * *}$ & $-41.97(1.06)^{* * *}$ & $-9.60(2.05)^{* * *}$ \\
\hline IV parameter & 1.0 (fixed) & $13.46(0.62)^{* * *}$ & $13.46(0.62)^{* * *}$ & $13.46(0.62)^{* * *}$ \\
\hline AIC & 347606.96 & 347606.96 & 347606.96 & 347606.96 \\
\hline Log Likelihood & -173666.48 & -173666.48 & -173666.48 & -173666.48 \\
\hline Num. obs. & 166554 & 166554 & 166554 & 166554 \\
\hline
\end{tabular}

${ }^{* * *} p<0.001 ;{ }^{* *} p<0.01 ;{ }^{*} p<0.05$.,

Base levels: Mode: Drive alone, Race: White; Income: Quintile 1; Education: Less than high school; Urban size: Not in an urban area.

Robust standard errors clustered by state. IV = Inclusive value (nesting parameter).

Table 4: Multinomial logistic regression of mode choice 